\title{
P04.03. Primary care providers' attitudes and beliefs about, and personal use of, complementary and alternative medicine (CAM)
}

\author{
M George ${ }^{1 *}$, A Johnson ${ }^{1}$, R Pinilla ${ }^{1}$, C Rand $^{2}$ \\ From International Research Congress on Integrative Medicine and Health 2012 \\ Portland, Oregon, USA. 15-18 May 2012
}

\section{Purpose}

To identify primary care providers' (PCP) attitudes and beliefs about, and personal use of, complementary and alternative medicine (CAM).

\section{Methods}

PCPs who referred patients into a research study about asthma self-management, including CAM, completed three surveys. The modified Integrative Medicine Attitude Questionnaire (m-IMAQ) is a 23-item survey that solicits beliefs about CAM and its role in treatment. The 10-item CAM Health Belief Questionnaire (CHBQ) asks about CAM attitudes and beliefs not included in the m-IMAQ. Lastly, the 30-item Morehouse College Survey of CAM Practices (MCSCAMP) characterizes PCPs personal CAM use. All subjects received a $\$ 100$ gift card for participation.

\section{Results}

Of the 21 referring PCPs, 14 physicians and two nurse practitioners (NPs) were enrolled. Seven were male (44\%); 13 White (81\%), two Asian (13\%) and one Black (6\%). The mean age in years of subjects was 45.7 and mean years in practice was 12.9; all but one was employed full-time. After reverse coding, higher m-IMAQ and CHBQ scores indicate more positive CAM orientation. All 16 providers (100\%) endorsed m-IMAQ items: "The spiritual beliefs of patients play an important role in their recovery"; "A strong relationship between patients and their providers is an extremely valuable therapeutic intervention that leads to improved outcomes"; and "In research, measuring quality of life is equally as important as measuring diseasespecific outcomes." Only one CHBQ item was endorsed by all: "A patient's expectations, health beliefs and values should be integrated into the patient care process." The MCSCAMP found prayer/spiritual healing to be the most common CAM for providers' personal use (50\%), followed by massage and acupuncture (19\%), music therapy, herbs and meditation (13\%).

\section{Conclusion}

PCPs in this sample have a positive CAM orientation uniformly endorsing items related to spirituality, the importance of patient-provider partnerships and quality of life. There was low personal use of CAM other than prayer by providers.

\section{Author details}

${ }^{1}$ University of Pennsylvania School of Nursing, Philadelphia, USA. ${ }^{2}$ Johns Hopkins University, Baltimore, USA.

Published: 12 June 2012

\section{doi:10.1186/1472-6882-12-S1-P273}

Cite this article as: George et al:: P04.03. Primary care providers' attitudes and beliefs about, and personal use of, complementary and alternative medicine (CAM). BMC Complementary and Alternative Medicine 2012 12(Suppl 1):P273.

${ }^{1}$ University of Pennsylvania School of Nursing, Philadelphia, USA

Full list of author information is available at the end of the article

(c) 2012 George et al; licensee BioMed Central Ltd. This is an Open Access article distributed under the terms of the Creative Commons 